\title{
Dynamic competition and resource partitioning during the early life of two widespread, abundant and ecologically similar fishes
}

\author{
A. D. Nunn • L. H. Vickers $\cdot$ K. Mazik $\cdot$ J. D. Bolland • G. Peirson • \\ S. N. Axford · A. Henshaw $\cdot$ I. G. Cowx
}

Received: 15 January 2020/Revised: 26 March 2020/Accepted: 30 March 2020/Published online: 18 April 2020

(C) The Author(s) 2020

\begin{abstract}
Competition and resource partitioning can have profound implications for individuals, populations and communities, and thus food webs, ecosystems and the management of biota and environments. In many species, the impacts of competition and resource partitioning are believed to be most severe during early life, but our understanding of the mechanisms and implications is incomplete. This study revealed short-term variations in both the occurrence and direction of competition during the early life of roach Rutilus rutilus and common bream Abramis brama, two of the most widespread and
\end{abstract}

Handling editor: Antti P. Eloranta

A. D. Nunn $(\bowtie) \cdot$ L. H. Vickers · J. D. Bolland .

I. G. Cowx

Hull International Fisheries Institute, Department of

Biological \& Marine Sciences, University of Hull,

Hull HU6 7RX, UK

e-mail: a.d.nunn@hull.ac.uk

K. Mazik

Department of Biological \& Marine Sciences, University

of Hull, Hull HU6 7RX, UK

G. Peirson

Environment Agency, Kidderminster DY11 7RA, UK

S. N. Axford

Environment Agency, York YO3 4UZ, UK

A. Henshaw

Environment Agency, Calverton NG14 6FZ, UK abundant fish species in Europe. There was also evidence of resource partitioning when small taxa dominated the zooplankton, but not when larger taxa were more abundant. In spite of the differences in foraging ecology, there were no significant differences in growth or nutritional condition in allopatry and sympatry. Similar to the concept of condition-specific competition, when competitive abilities vary along environmental gradients, the impacts of interspecific interactions on foraging ecology, growth and condition are dynamic and likely vary according to temporal fluctuations in prey availability. This is important because short-term incidences of competition could have cascading effects on food webs, even when no impacts on growth rates or condition are detected.

Keywords Behaviour - Condition · Foraging · Growth · Prey selection · Trophic niche

\section{Introduction}

Competition and resource partitioning can have profound implications for individuals, populations and communities, and thus food webs and ecosystems. Competition occurs when inter-individual interactions reduce access to resources that are directly or indirectly related to growth, fitness or survival. For example, competition may cause animals to switch to less nutritional prey and have lower growth rates, 
which can have implications for fecundity or nutritional condition (Byström et al., 1998), and plants may compete for light, nutrients or water (Aschehoug et al., 2016). Interspecific competition is the principal mechanism leading to resource partitioning, and may be demonstrated by species differing in their resource use in allopatry and in sympatry with competitors (Bolnick et al., 2010). Indeed, intense competition between ecologically similar species can culminate in the exclusion of subordinates from overlapping fundamental niches (Tran et al., 2015). Conversely, resource partitioning, such as when sympatric species reduce overlap in their realised niches by consuming different prey, may facilitate the co-existence of ecologically similar species, avoid potential recruitment bottlenecks, and increase population and community stability by reducing the effects of competition (Schellekens et al., 2010).

Competition and resource partitioning have received considerable attention across a diverse range of biota, including algae, protozoans, macroinvertebrates, higher plants and vertebrates (see Begon et al., 2006). Werner \& Hall (1976), for example, observed that three congeneric sunfish species segregated ecologically when together, but consumed larger prey and had higher growth rates when alone; niche shifts were indicated by convergence of the species' foraging behaviour in allopatry. Similarly, a series of field experiments demonstrated that, owing to a superior efficiency when foraging on zooplankton, a generalist cyprinid had a negative impact on the individual growth rates of a distantly related percid via competition for food (Persson, 1983a, 1987; Persson \& Greenberg, 1990). More recently, competition has been examined in relation to the invasion success and impacts of alien species (e.g. Tran et al., 2015; Buoro et al., 2016; Britton et al., 2018). Interactions between species with size-structured populations can be complex, however, as resource use and functional roles often differ markedly between size classes or during ontogeny (Sánchez-Hernández, 2016; Sánchez-Hernández et al., 2019). In fish, competition is generally believed to be of greatest significance in the larval or juvenile periods (Beaugrand et al., 2003), probably because they are less morphologically and behaviourally differentiated than later in development, frequently occur in mixed-species shoals and often have similar diets (Nunn et al., 2007a, 2012). Despite this, few studies have examined competition and resource partitioning in young fishes, especially the consequences of temporal variations in resource availability, and our understanding of the mechanisms and implications is incomplete. This is important because early ontogeny is invariably the critical period in the life cycle of fishes, with competition-induced changes in individual growth rates, condition or survival having direct implications for adult cohort size and population and community dynamics (Beaugrand et al., 2003; Fletcher et al., 2019). Furthermore, as fish are key predators in the majority of aquatic environments, competition and resource partitioning can have tangible impacts on energy pathways, foodweb dynamics and ecosystem functioning (Miller \& Rudolf, 2011; Nakazawa, 2015).

This study examined exploitative competition and resource partitioning during the early life of roach Rutilus rutilus (L.) and common bream Abramis brama (L.), two of the most widespread and abundant fishes in Europe (Kottelat \& Freyhof, 2007). These species were chosen because they are ecologically similar (Hayden et al., 2010; Jarolím et al., 2010) and therefore have the potential to compete for resources (Buoro et al., 2016), especially in the larval and juvenile periods when they frequently occur together (Nunn et al., 2007a). The objectives were to compare trophic niches, niche breadths, prey selection, growth and nutritional condition in allopatry and sympatry, the rationale being that competition-induced changes in any of these parameters could have profound implications for individual survival and population dynamics, as well as food webs and ecosystem processes. Although it is generally believed that bream are more efficient than roach when foraging on zooplankton in the juvenile and adult periods (Winfield et al., 1983; Townsend et al., 1986; Diehl, 1988; Winfield \& Townsend, 1988; Garner, 1996; but see Persson \& Brönmark, 2002), the consequences of variations in resource availability for interactions between the two species during the larval period are unknown. It was hypothesised that trophic niches, niche breadths and prey selection would differ in allopatry and sympatry, with negative consequences for growth and nutritional condition in sympatry, but that foraging ecology would vary over time, according to fluctuations in resource availability. Knowledge of the occurrence and potential implications of competition and resource partitioning is essential for the 
effective conservation and management of biota and their environments.

\section{Materials and methods}

\section{Experimental design}

Nine mesocosms $(60 \mathrm{~cm}$ long $\times 60 \mathrm{~cm}$ wide $\times 100$ $\mathrm{cm}$ high, 1-mm mesh) were placed $60 \mathrm{~cm}$ apart in an aquaculture pond ( $80 \mathrm{~cm}$ deep, $700 \mathrm{~m}^{2} ; 53^{\circ} 1^{\prime} 59^{\prime \prime} \mathrm{N}$, $1^{\circ} 3^{\prime} 3^{\prime \prime} \mathrm{W}$ ) using a Latin-square experimental design. A total of 100 larvae (roach mean \pm S.D. standard length, $\quad L_{\mathrm{S}}=7.9 \pm 0.7 \mathrm{~mm} ; \quad$ bream $=10.0 \pm 0.8$ $\mathrm{mm}$ ) from the aquaculture facility's hatchery was stocked into each mesocosm, to replicate one of three treatments (each with three replicates): 100 roach (in allopatry), 100 bream (in allopatry), 50 roach and 50 bream (in sympatry). The fish were stocked to coincide with a peak in zooplankton abundance and left to acclimatise for 3 days (cf. Rodríguez-Lozano et al., 2016; Krabbenhoft et al., 2017; Cano-Rocabayera

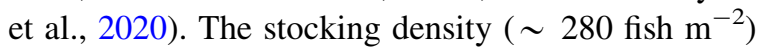
was within the range observed in the mainstem of a nearby lowland river (0-821 fish $\mathrm{m}^{-2}$, summer mean 85 fish $\mathrm{m}^{-2}$; Nunn et al., 2007a), and the 1:1 ratio in the sympatry treatment was selected to test for asymmetries in the competitive relationship (Young, 2004). The mesocosms provided fish access to both the water column and benthos, and were intended to allow free movement of zooplankton, to reflect natural spatial and temporal variations in their abundance in the pond (there was no significant difference in zooplankton abundance in the mesocosms and pond; paired $t$ test, $t=-0.663$, df $=6, P=0.532$ ).

Zooplankton samples were collected during daylight from each mesocosm every 2-3 days by pouring $10 \mathrm{~L}$ of water through a sieve (100- $\mu \mathrm{m}$ mesh) (Tewson et al., 2016). Whilst the mesh size of the sieve likely underestimates the densities of the smallest rotifers, it was considered satisfactory for the sizes eaten by roach and bream larvae (Nunn et al., 2007b, c). A minimum of ten individuals of both fish species was then removed at random from each mesocosm, euthanised with an overdose of MS222 and preserved in $4 \%$ formalin solution for diet analysis (see below), with replacements stocked to maintain a constant density (to avoid the additional complication of changes in the abundance of potential competitors during the experiment). The experiment was intended to assess any impacts of competition and resource partitioning on the trophic niches, niche breadths and prey selection of the two species, and ceased when natural food resources declined (on 19 June; day 16). Identical treatments were used in a further experiment at the same time in the following year, again coinciding with a peak in zooplankton abundance, in which all fish remained in the mesocosms until natural food resources declined (on 4 June; day 22), the intention being to assess any impacts of competition and resource partitioning on fish growth and condition. The fish were stocked at approximately the same size as in the first experiment.

\section{Data collection}

For the first experiment (trophic niches, niche breadths and prey selection), the contents of the entire gastrointestinal tract were removed from individual roach $(n=333)$ and bream $(n=361)$ pterolarvae (finformed larvae), identified to the lowest practicable taxonomic level under a binocular microscope and enumerated; biofilm (the periphyton and associated microfauna that grow on underwater surfaces) was recorded as percent volume and converted to 'number' using the relationship between percent volume of biofilm and the number and percent volume of 'non-biofilm' (Nunn et al., 2007b). Each zooplankton sample was made up to $100 \mathrm{~mL}$ and thoroughly mixed before withdrawing a 500- $\mu \mathrm{L}$ sub-sample with a wide-bore, automatic pipette (Nunn et al., 2007a, c; Tewson et al., 2016). Sub-samples were emptied into a Sedgewick Rafter counting chamber, and all organisms were identified to the lowest practicable taxonomic level under a binocular microscope and enumerated. Three sub-samples were analysed for each sample. At the end of the second experiment (growth and condition), a minimum of 30 fish from each mesocosm (roach $n=191$, bream $n=184$ ) were dried of excess moisture using blotting paper, weighed (nearest $\mathrm{mg}$ ) using an electronic balance, and measured $\left(L_{\mathrm{S}}\right.$, nearest $0.1 \mathrm{~mm}$ ) under a binocular microscope.

\section{Data analysis}

Bray-Curtis similarity matrices (Bray \& Curtis, 1957) were calculated using the abundance (square-root transformed) of each taxon in the diet of each fish and 
ordinated (group centroids with trajectories) using non-metric multidimensional scaling (MDS) to investigate trophic niche overlap in roach and bream larvae in allopatry and sympatry (Clarke \& Warwick, 2001). The matrices were tested for homogeneity of dispersions using permutational analysis of multivariate dispersions, and then submitted to permutational multivariate analysis of variance (PERMANOVA; 9999 random permutations) with pair-wise comparisons, using a two-way factorial design accounting for treatment (fixed factor, nested in time) and time (random factor), to assess the significance of any competition (differences in the trophic niches of allopatric and sympatric fish; Werner \& Hall, 1976; Bolnick et al., 2010), and also differences between sampling occasions (Anderson, 2001; Anderson et al., 2008; Rodríguez-Lozano et al., 2016; Gilby et al., 2017). Mesocosm number was included as a random factor but had no effect, so data were pooled from each treatment for further analysis (Jackson et al., 2013). In addition, similarity percentages (SIMPER) analysis was used to calculate the percentage contributions of each taxon to dissimilarities in the trophic niches of allopatric and sympatric fish (Clarke \& Warwick, 2001). PERMANOVA and SIMPER were also used to examine (i) resource partitioning (trophic niche overlap; Schoener, 1974; Britton et al., 2018) in sympatric roach and bream larvae, and (ii) variations in zooplankton assemblage structure between treatments and over time. The relationship between prey diversity (Shannon-Wiener's $H^{\prime}, \log _{\mathrm{e}}$ ) and trophic niche overlap (\%) was calculated using linear regression, and trophic niche breadths-mean $H^{\prime}$ and mean Pielou's dietary evenness $\left(J^{\prime}\right)$ (Washington, 1984)—of roach and bream larvae were compared in allopatry and sympatry using independent samples $t$-tests.

The prey selection of roach and bream larvae was investigated using the relativized electivity index: $E_{\mathrm{i}}^{*}=\left(W_{\mathrm{i}}-n^{-1}\right)\left(W_{\mathrm{i}}+n^{-1}\right)^{-1}$, where $n$ is the number of prey types available and $W_{\mathrm{i}}$ is estimated by $W_{\mathrm{i}}=\left(r_{\mathrm{i}} p_{\mathrm{i}}^{-1}\right)\left(\sum\left(r_{\mathrm{i}} p_{\mathrm{i}}^{-1}\right)\right)^{-1}$, where $r_{\mathrm{i}}$ and $p_{\mathrm{i}}$ are the percentage of prey type $i$ in the diet and environment, respectively (Vanderploeg \& Scavia, 1979). E* ranges from -1 to +1 , with negative values indicating avoidance, positive values indicating selection, and 0 representing no preference. Prey selection was examined in combination with trophic niche and niche breadth in an attempt to identify the causes of any differences in foraging ecology in allopatry and sympatry.

Mean $L_{\mathrm{S}}$ and wet weights of roach and bream were compared in allopatry and sympatry using independent samples $t$-tests, and $\ln$ wet weight- $\ln L_{\mathrm{S}}$ relationships were compared using analysis of covariance (ANCOVA). The $\ln$ wet weight $-\ln L_{\mathrm{S}}$ relationships were also used to calculate the relative body condition factor ( $K$; Bagenal \& Tesch, 1978) of roach and bream in allopatry and sympatry, which were compared using independent samples $t$-tests. Statistical analyses were conducted using PRIMER (v. 7) \& PERMANOVA+ (PRIMER-E Ltd, Plymouth, UK) and SPSS (v. 24, SPSS Inc., Chicago, USA).

\section{Results}

\section{Competition}

Planktonic rotifers and copepod nauplii were the most common prey of roach and bream larvae in both allopatry and sympatry on the majority of sampling occasions (Fig. 1). Notwithstanding, there were significant differences in the trophic niches of roach larvae in allopatry and sympatry on two occasions (PERMANOVA, $\quad$ pseudo- $F=2.762, \quad$ df $=7$, $P<0.001$ ) (Fig. 2a). On one occasion (day 5), copepod nauplii and planktonic rotifers were most important in allopatry, whereas biofilm and ostracods were most important in sympatry (Table 1). On the other occasion (day 11), copepod nauplii and Daphnia magna Straus were most important in allopatry, with rotifers and Chydorus spp. most important in sympatry (Table 1). There were no significant differences in the niche breadths of roach larvae in allopatry and sympatry (independent samples $t$-tests, all $P>0.05$ ).

There were significant differences in the trophic niches of bream larvae in allopatry and sympatry on three occasions (PERMANOVA, pseudo- $F=2.318$, df $=7, P<0.001$ ) (Fig. 2b). On the first occasion (day 3 ), rotifers were most important in allopatry, whereas biofilm, cyclopoid copepods and phytoplankton were most important in sympatry (Table 2). Copepod nauplii, biofilm, ostracods and cyclopoid copepods were most important in allopatry on the second occasion (day 7), with rotifers most important in sympatry (Table 2). On the third occasion (day 16), rotifers and biofilm were most important in allopatry, 


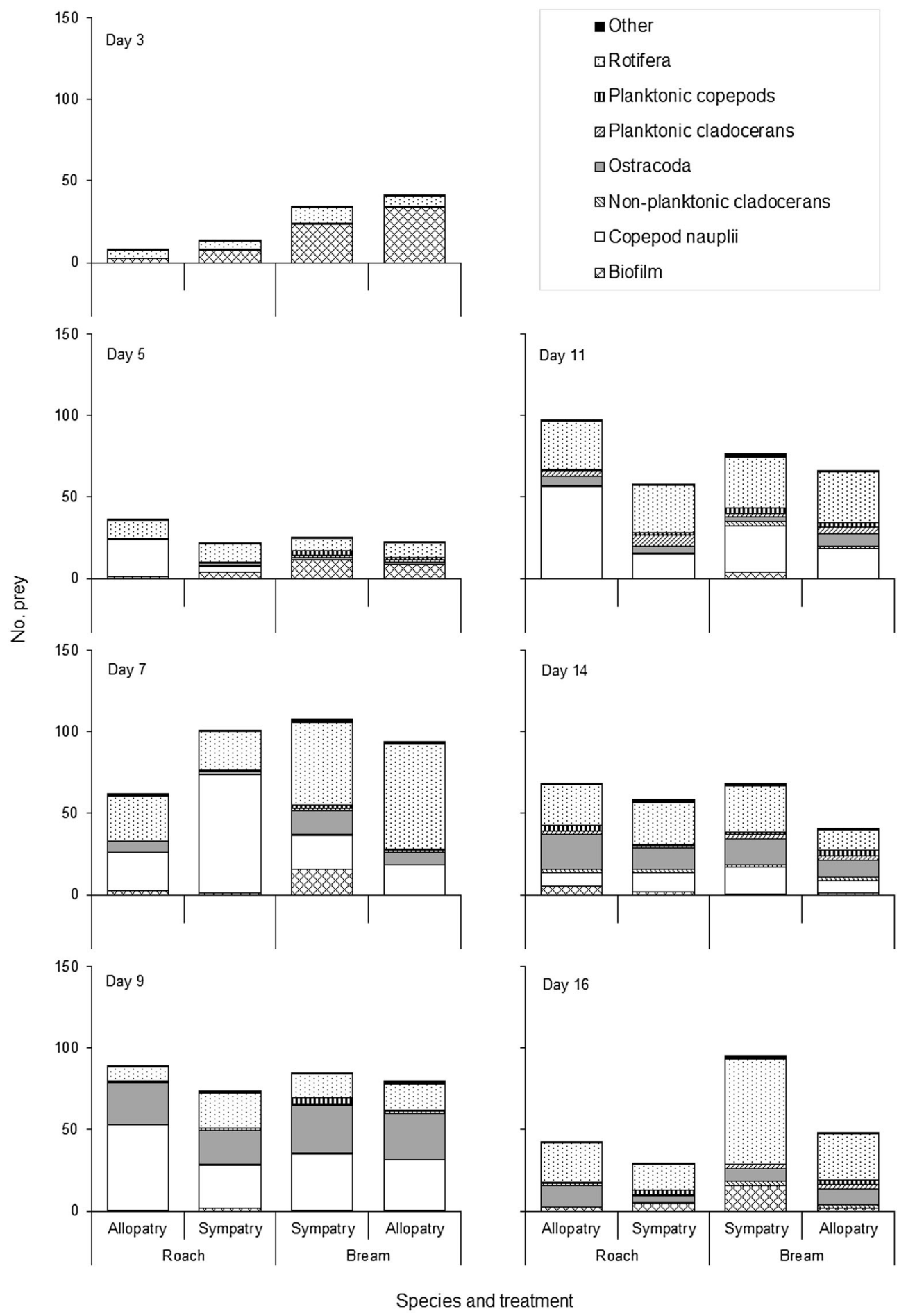

Fig. 1 Mean diet composition of roach and common bream larvae in allopatry and sympatry on seven sampling occasions 
(a)

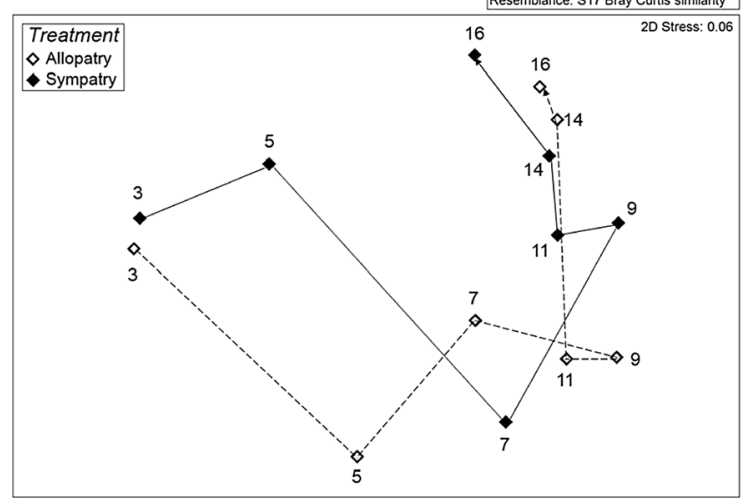

(b)

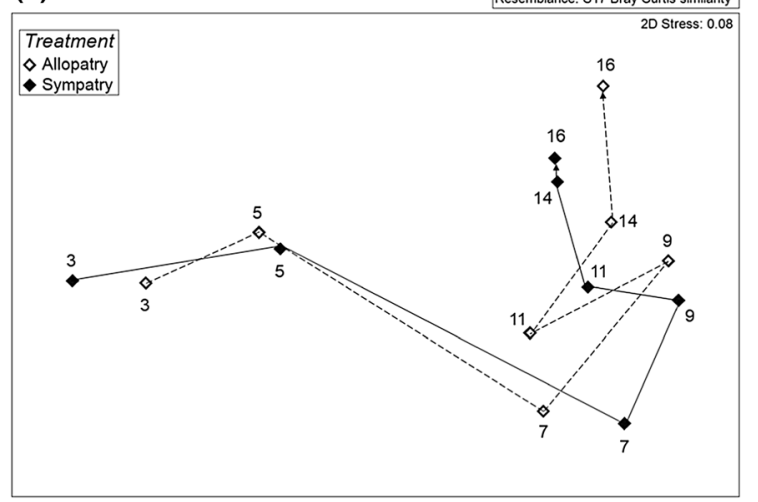

\begin{tabular}{|ll|}
\hline (c) & $\begin{array}{l}\text { Transtorm: Square root } \\
\text { Resemblance: } S 17 \text { Bray Curits simianity }\end{array}$ \\
\hline
\end{tabular}

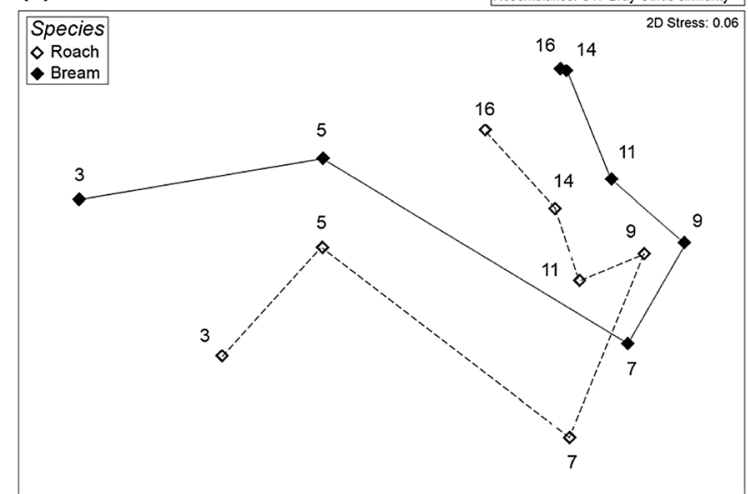

Fig. 2 Non-metric multidimensional scaling ordination plots comparing the trophic niche of a roach larvae in allopatry and sympatry, b common bream larvae in allopatry and sympatry, and c sympatric roach and common bream larvae, using group centroids with trajectories over seven sampling occasions (days $3,5,7,9,11,14$ and 16)

whereas ostracods, D. magna and cyclopoid copepods were most important in sympatry (Table 2). There were significant differences in the niche breadths of bream larvae in allopatry and sympatry on two occasions (independent samples $t$-tests, all $P<0.05$ ).
Resource partitioning

There was a negative relationship between trophic niche overlap and prey diversity (linear regression, $y=-18.183 x+39.473, \quad$ df $=6, \quad r^{2}=0.634$, $P=0.032$ ), and significant differences in the trophic niches of sympatric roach and bream larvae on four occasions (days 3, 5, 7 and 14; PERMANOVA, pseudo- $F=3.079$, df $=7, P<0.001$ ) (Fig. 2c). In all cases, copepod nauplii were more important in the diets of roach than in the diets of bream (Table 3).

Prey abundance

Planktonic rotifers were the most abundant zooplankters on $71 \%$ of sampling occasions, followed by ostracods (19\%) and copepod nauplii (10\%); cladocerans (Alona spp., Bosmina sp., Chydorus spp., D. magna) and cyclopoid copepods were recorded in smaller numbers (Fig. 3). Zooplankton assemblage structure varied over time (PERMANOVA, pseudo$F=17.643$, df $=6, P<0.001$ ), but there was no significant difference between treatments (roach vs. bream vs. roach and bream) (PERMANOVA, pseudo$F=0.699$, df $=7, P=0.857)$.

\section{Prey selection}

There were no consistent differences in the prey selection of roach and bream larvae in allopatry and sympatry. In both treatments, roach larvae avoided Alona spp., Chydorus spp., cyclopoid copepods and $D$. magna ( $E^{*}$ was negative), although avoidance of the latter two taxa was most often strongest in allopatry (Fig. 4). By contrast, copepod nauplii were selected ( $E^{*}$ was positive) in both treatments or, in one case, consumed in proportion to their abundance $\left(E^{*} \approx 0\right)$, and there was no consistent preference for ostracods or planktonic rotifers (Fig. 4). Bream larvae avoided Alona spp. and Chydorus spp. in both allopatry and sympatry, but there was no consistent preference for copepod nauplii, cyclopoid copepods, D. magna, ostracods or rotifers (Fig. 4).

\section{Growth and condition}

There were no significant differences in the mean lengths, weights, nutritional condition or weight- 
Table 1 Similarity percentages (SIMPER) analysis of the mean abundances (square-root transformed) of key prey taxa and their contributions $(\%)$ to dissimilarities in the diets of roach larvae in allopatry and sympatry

\begin{tabular}{|c|c|c|c|c|c|c|c|}
\hline \multirow[b]{2}{*}{ Taxon } & \multicolumn{2}{|c|}{ Day $5^{\mathrm{a}}$} & \multirow[b]{2}{*}{$\%$} & \multirow[b]{2}{*}{ Taxon } & \multicolumn{2}{|c|}{ Day $11^{\mathrm{b}}$} & \multirow[b]{2}{*}{$\%$} \\
\hline & Allo. & Sym. & & & Allo. & Sym. & \\
\hline Copepod nauplii & 3.7 & 0.5 & 38.0 & Copepod nauplii & 5.4 & 2.3 & 34.1 \\
\hline Rotifera & 3.1 & 2.9 & 18.3 & Rotifera & 4.5 & 4.6 & 22.8 \\
\hline Biofilm & 0.3 & 1.4 & 15.8 & Daphnia magna & 1.2 & 1.1 & 12.6 \\
\hline Ostracoda & 0.3 & 0.8 & 9.1 & Ostracoda & 1.6 & 1.6 & 11.7 \\
\hline Phytoplankton & 0.4 & 0.4 & 6.3 & Chydorus spp. & 0.3 & 0.4 & 4.4 \\
\hline Mean dissimilarity & & & 62.0 & Mean dissimilarity & & & 58.6 \\
\hline
\end{tabular}

Allo. allopatry, Sym. sympatry

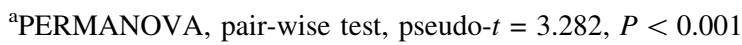

${ }^{\mathrm{b}}$ PERMANOVA, pair-wise test, pseudo- $t=1.659, P=0.041$

Table 2 Similarity percentages (SIMPER) analysis of the mean abundances (square-root transformed) of key prey taxa and their contributions $(\%)$ to dissimilarities in the diets of common bream larvae in allopatry and sympatry

\begin{tabular}{|c|c|c|c|c|c|c|c|c|c|c|c|}
\hline \multirow[b]{2}{*}{ Taxon } & \multicolumn{2}{|c|}{ Day $3^{\mathrm{a}}$} & \multirow[b]{2}{*}{$\%$} & \multirow[b]{2}{*}{ Taxon } & \multicolumn{2}{|c|}{ Day $7^{b}$} & \multirow[b]{2}{*}{$\%$} & \multirow[b]{2}{*}{ Taxon } & \multicolumn{2}{|c|}{ Day $16^{\mathrm{c}}$} & \multirow[b]{2}{*}{$\%$} \\
\hline & Allo. & Sym. & & & Allo. & Sym. & & & Allo. & Sym. & \\
\hline Biofilm & 3.8 & 5.1 & 55.7 & Rotifera & 6.2 & 7.0 & 24.4 & Rotifera & 6.1 & 4.2 & 33.4 \\
\hline Rotifera & 2.9 & 2.3 & 21.1 & Copepod nauplii & 3.6 & 2.6 & 20.4 & Ostracoda & 2.3 & 2.6 & 13.4 \\
\hline Cyclopoida & 0.3 & 0.4 & 8.4 & Biofilm & 3.0 & 0.0 & 15.9 & Biofilm & 1.5 & 0.6 & 10.6 \\
\hline \multirow[t]{2}{*}{ Phytoplankton } & 0.1 & 0.2 & 4.6 & Ostracoda & 3.0 & 1.8 & 15.6 & Daphnia magna & 0.4 & 1.1 & 8.5 \\
\hline & & & & Cyclopoida & 1.1 & 0.2 & 6.5 & Cyclopoida & 0.1 & 0.9 & 7.5 \\
\hline Mean dissimilarity & & & 42.2 & Mean dissimilarity & & & 55.1 & Mean dissimilarity & & & 61.1 \\
\hline
\end{tabular}

Allo. allopatry, Sym. sympatry

${ }^{\text {a}}$ PERMANOVA, pair-wise test, pseudo- $t=1.752, P=0.037$

${ }^{\mathrm{b}}$ PERMANOVA, pair-wise test, pseudo- $t=2.514, P=0.001$

${ }^{\mathrm{c}}$ PERMANOVA, pair-wise test, pseudo- $t=1.821, P=0.004$

length relationships of roach or bream in allopatry and sympatry (Table 4).

\section{Discussion}

This study revealed short-term variations in both the occurrence and direction of competition during the early life of roach and bream, two of the most widespread and abundant fish species in Europe, with significant differences in the trophic niches of bream in allopatry and sympatry on three occasions. When planktonic rotifers were most abundant and dominated the zooplankton (91\%; on day 3), they were most important in allopatry, whereas biofilm, adult cyclopoid copepods and phytoplankton were most important in sympatry. This was reflected by the marginally higher electivity values for rotifers and cyclopoid copepods in allopatry and sympatry, respectively. This is potentially significant because many fish species, including bream, select or consume large quantities of rotifers during the larval period but generally avoid or consume biofilm, copepods and phytoplankton in comparatively small quantities (Nunn et al., 2012). In accordance with the predictions of the optimal foraging theory (Werner \& Hall, 1974), the extensive 
Table 3 Similarity percentages (SIMPER) analysis of the mean abundances (square-root transformed) of key prey taxa and their contributions $(\%)$ to dissimilarities in the diets of sympatric roach and common bream larvae

\begin{tabular}{|c|c|c|c|c|c|c|c|c|c|c|c|c|c|c|c|}
\hline \multirow[b]{2}{*}{ Taxon } & \multicolumn{2}{|c|}{ Day $3^{\mathrm{a}}$} & \multirow[b]{2}{*}{$\%$} & \multirow[b]{2}{*}{ Taxon } & \multicolumn{2}{|c|}{ Day $5^{\mathrm{b}}$} & \multirow[b]{2}{*}{$\%$} & \multirow[b]{2}{*}{ Taxon } & \multicolumn{2}{|c|}{ Day $7^{\mathrm{c}}$} & \multirow[b]{2}{*}{$\%$} & \multirow[b]{2}{*}{ Taxon } & \multicolumn{2}{|c|}{ Day $14^{\mathrm{d}}$} & \multirow[b]{2}{*}{$\%$} \\
\hline & $\mathrm{R}$ & B & & & $\mathrm{R}$ & B & & & $\mathrm{R}$ & $\mathrm{B}$ & & & $\mathrm{R}$ & B & \\
\hline Biofilm & 1.5 & 5.1 & 57.5 & Biofilm & 1.4 & 2.0 & 24.8 & $\begin{array}{r}\text { Copepod } \\
\text { nauplii }\end{array}$ & 6.5 & 2.6 & 37.8 & Rotifera & 4.6 & 2.6 & 24.8 \\
\hline Rotifera & 1.8 & 2.3 & 20.4 & Rotifera & 2.9 & 2.6 & 24.0 & Rotifera & 3.8 & 7.0 & 32.0 & Ostracoda & 2.8 & 2.5 & 18.9 \\
\hline Phytoplankton & 0.5 & 0.2 & 8.2 & Ostracoda & 0.8 & 0.5 & 12.0 & Ostracoda & 0.9 & 1.8 & 12.1 & $\begin{array}{r}\text { Copepod } \\
\text { nauplii }\end{array}$ & 1.2 & 0.9 & 13.3 \\
\hline \multirow{3}{*}{$\begin{array}{r}\text { Copepod } \\
\text { nauplii }\end{array}$} & 0.4 & 0.1 & 6.6 & Cyclopoida & 0.2 & 0.7 & 8.9 & & & & & Cyclopoida & 0.3 & 1.1 & 9.8 \\
\hline & & & & $\begin{array}{r}\text { Daphnia } \\
\text { magna }\end{array}$ & 0.2 & 0.5 & 7.4 & & & & & $\begin{array}{r}\text { Daphnia } \\
\text { magna }\end{array}$ & 0.5 & 1.0 & 7.8 \\
\hline & & & & $\begin{array}{r}\text { Copepod } \\
\text { nauplii }\end{array}$ & 0.5 & 0.1 & 6.8 & & & & & $\begin{array}{l}\text { Chydorus } \\
\text { spp. }\end{array}$ & 0.6 & 0.7 & 7.8 \\
\hline Dissimilarity & & & 59.3 & Dissimilarity & & & 57.1 & Dissimilarity & & & 58.5 & Dissimilarity & & & 59.6 \\
\hline
\end{tabular}

$R$ roach, $B$ common bream

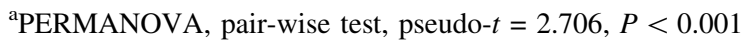

${ }^{\mathrm{b}}$ PERMANOVA, pair-wise test, pseudo- $t=1.581, P=0.027$

${ }^{\mathrm{c}}$ PERMANOVA, pair-wise test, pseudo- $t=2.232, P=0.004$

${ }^{\mathrm{d}}$ PERMANOVA, pair-wise test, pseudo- $t=1.954, P=0.005$

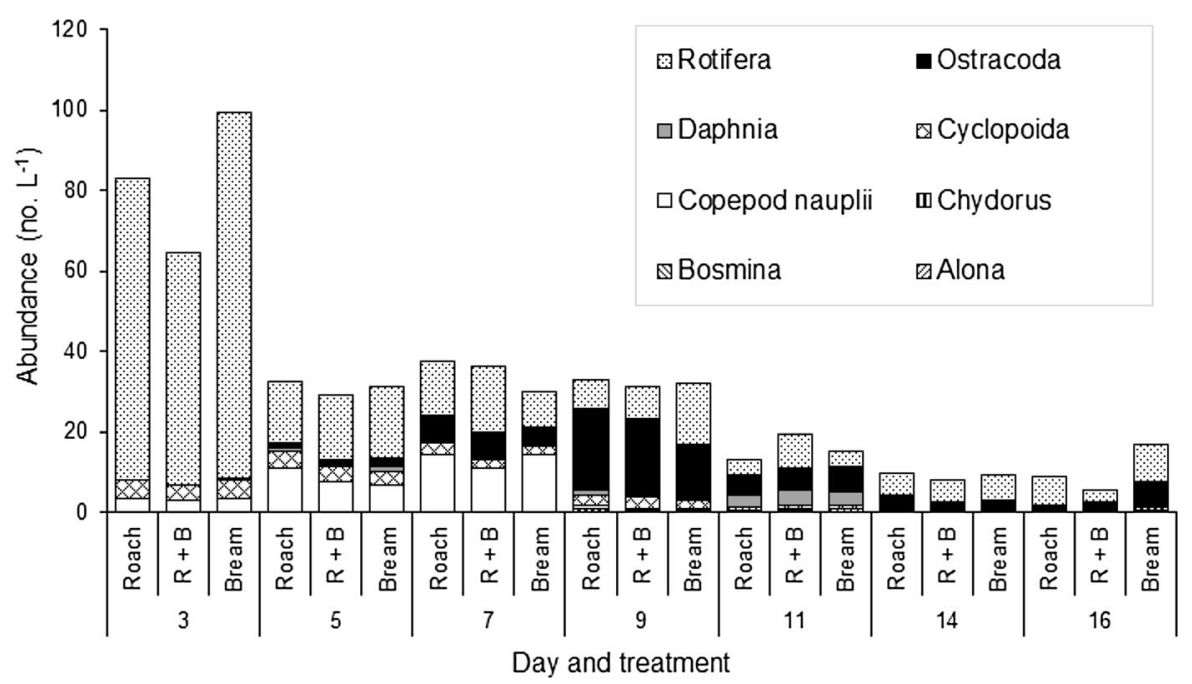

Fig. 3 Zooplankton composition in the presence of roach, common bream, and roach and common bream larvae on seven sampling occasions

consumption of rotifers is believed to be due to their high abundance, ubiquity and ease of capture and ingestion, whereas biofilm and phytoplankton are considered poor food resources because of their low digestibility and nutritive value (Persson, 1983b; Nunn et al., 2007c). Indeed, although bream larvae sometimes consume biofilm and phytoplankton, it is generally only when animal prey are scarce (Garner, 1996). Many fish species, including bream, find copepods comparatively difficult to capture and preferentially feed upon less evasive zooplankters (Persson, 1987; Winfield \& Townsend, 1988). It therefore 


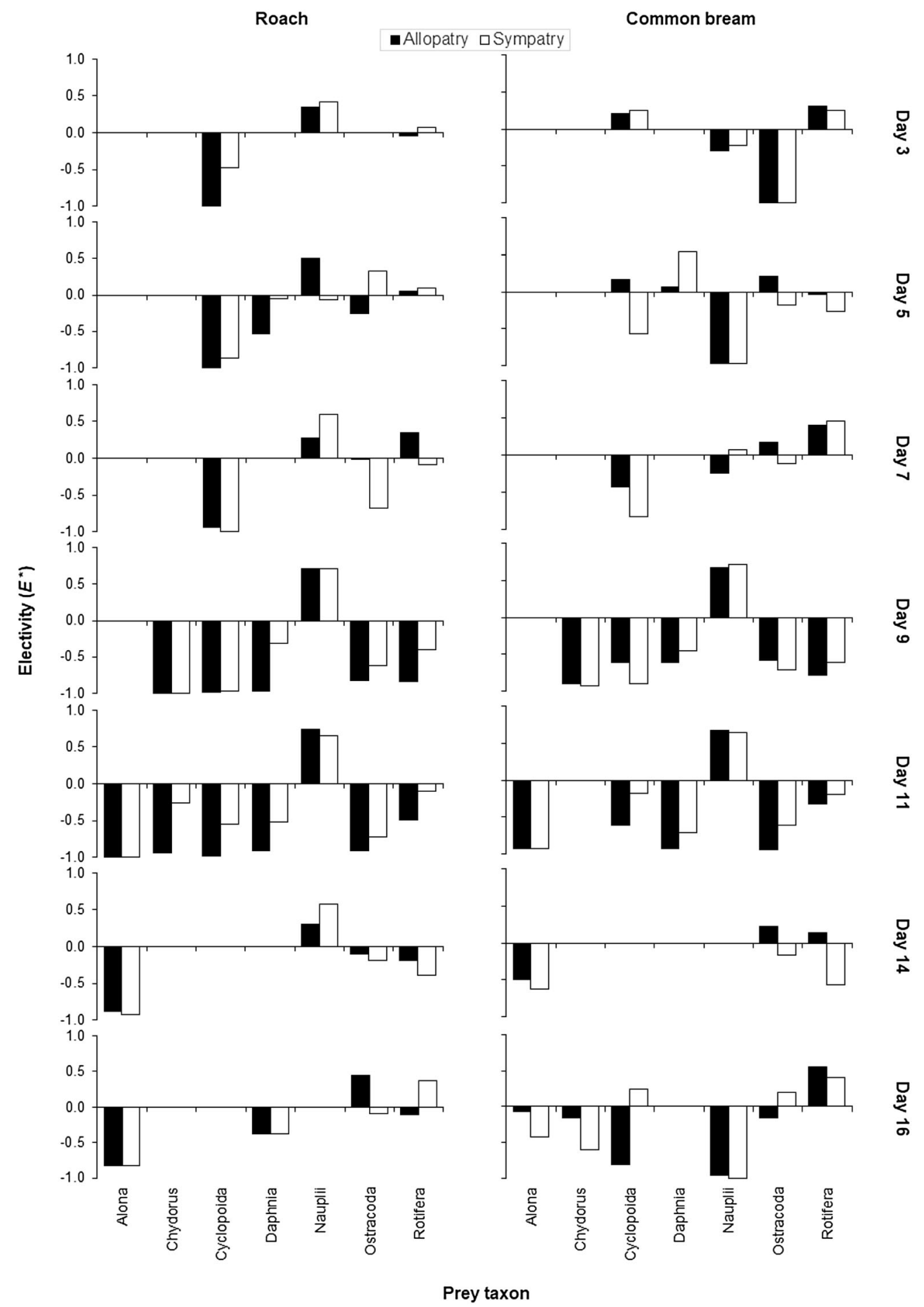

Fig. 4 Prey selection of roach and common bream larvae in allopatry and sympatry on seven sampling occasions

seems that, although there was no significant effect on niche breadth, roach caused bream to forage on suboptimal prey.
When planktonic rotifers and copepod nauplii were equally abundant (both 38\%; on day 7), copepod nauplii, biofilm, ostracods and cyclopoid copepods 
were most important in allopatry, whereas rotifers were most important in sympatry. Many fish larvae select rotifers over similar-sized copepod nauplii and avoid biofilm, ostracods and cyclopoid copepods (Winfield \& Townsend, 1988; Nunn et al., 2007c), so the greater importance of 'sub-optimal' prey in allopatry could suggest that intraspecific competition was stronger than interspecific competition. However, it could also be explained by "switching", when prey are eaten disproportionately often when they are common and disproportionately rarely when they are uncommon (Townsend et al., 1986), as copepod nauplii and cyclopoid copepods were marginally more abundant in allopatry, whereas rotifers were more abundant in sympatry. This was reflected by the stronger avoidance of cyclopoid copepods and ostracods and stronger selection of rotifers in sympatry. The availability of biofilm is unknown, but its greater importance, and the greater importance of ostracods, in allopatry suggests that benthic foraging was more prevalent than in sympatry. Together, the various results suggest that bream was the superior competitor, as rotifers ('preferred' prey) were of greatest importance in the diets of roach in allopatry, despite being more abundant in sympatry, whereas copepod nauplii (less preferable prey) were of greatest importance in sympatry, despite being more abundant in allopatry.

When the relative abundance of rotifers in the zooplankton was high (62\%) but absolute abundance was low (on day 16), they and biofilm were most important in allopatry, whereas ostracods, D. magna and cyclopoid copepods were most important in sympatry. This was reflected by the electivity value for rotifers being highest in allopatry, and those of ostracods and cyclopoid copepods being highest in sympatry. For the reasons described previously, the higher importance of rotifers in allopatry, and ostracods and copepods in sympatry, suggests that roach caused bream to forage on sub-optimal prey. By contrast, the higher importance of biofilm (generally a poor food resource) in allopatry and D. magna (generally a profitable food resource) in sympatry initially appears counterintuitive. The higher importance of biofilm in allopatry could suggest that animal prey were scarce (Garner, 1996), possibly because intraspecific competition was stronger than interspecific competition. Indeed, the mean number of animal prey consumed in allopatry was half the number consumed in sympatry. Alternatively, it could be a reflection of a greater availability of biofilm in allopatry. The availability of biofilm is unknown, but the explanation for the higher importance of D. magna in sympatry is probably that, due to the naturally contagious distribution of zooplankters, they were less abundant in allopatry, as none were detected in the zooplankton.

There was also evidence for a competitive effect of bream on the trophic niche of roach larvae. When rotifers $(53 \%)$ were twice as abundant as copepod nauplii (27\%) (on day 5), both were more important in allopatry than in sympatry, whereas biofilm and ostracods were most important in sympatry, suggesting a greater importance of planktivory in allopatry and benthivory in sympatry. This was reflected partially by the electivity values for copepod nauplii and ostracods being higher in allopatry and sympatry, respectively. This is potentially significant because roach larvae preferentially forage upon planktonic prey and invariably only switch to benthic resources when zooplankton is scarce (Townsend et al., 1986; Garner, 1996). A similar phenomenon has been observed in Eurasian perch Perca fluviatilis L., which feed mainly upon planktonic cladocerans in allopatry but copepods and/or benthic macroinvertebrates in the presence of roach, probably because roach are competitively superior when foraging on zooplankton (Persson \& Greenberg, 1990). Juvenile bream have a protrusible mouth and greater strike ability than juvenile roach, so could possess a competitive advantage when foraging on zooplankton (Winfield et al., 1983; Winfield \& Townsend, 1988), but it is unclear whether that is also the case in the larval period. Notwithstanding, it is possible that bream caused an increase in the consumption of benthic resources by roach.

By contrast, there was no obvious difference in foraging mode (e.g. zooplanktivory vs. benthivory) when the zooplankton was characterised by low abundances of rotifers (32\%), ostracods (36\%) and D. magna (22\%) (on day 11), with copepod nauplii and D. magna most important in the diet in allopatry, and rotifers and Chydorus spp. most important in sympatry. This was reflected partially by the electivity values for copepod nauplii being highest in allopatry, and rotifers and Chydorus spp. being highest in sympatry. Although roach larvae invariably select planktonic over non-planktonic cladocerans, and rotifers over copepod nauplii (Winfield et al., 1983; 
Townsend et al., 1986; Nunn et al., 2007c), there was no obvious difference in the importance of 'preferred' (D. magna, planktonic rotifers) and less favourable (copepod nauplii, Chydorus spp.) prey in allopatry and sympatry. The greater importance of rotifers in sympatry is probably because they were more than twice as abundant than in allopatry. By contrast, copepod nauplii and D. magna were more important in allopatry despite being more abundant in sympatry, and vice versa for Chydorus spp., suggesting bream caused a shift in roach foraging behaviour.

There was evidence of resource partitioning in the trophic niches of sympatric roach and bream larvae when small taxa (copepod nauplii and/or rotifers) dominated the zooplankton ( $>70 \%$ abundance), but not when the relative abundance of larger taxa was greater than $\sim 30 \%$. According to the competitive exclusion principle (Hardin, 1960), this suggests that competition was strongest when small taxa dominated the zooplankton, presumably because their availability was below the resource-limitation threshold and insufficient to meet both fish species' energetic requirements. Conversely, it is possible that competition was strongest when the relative abundance of larger zooplankters was highest, as competition can result in increases in trophic niche similarity among ecologically similar species (Cucherousset et al., 2007); it is also possible for resource partitioning to be high when resources are limited, but low when they are abundant or rare (Wiens, 1993). Whether competition results in divergence or convergence of the trophic niches of sympatric species is likely influenced by the diversity of potential prey, with high diversity increasing the potential for interactive segregation in resource use (Hillebrand \& Matthiessen, 2009). Indeed, Sánchez-Hernández et al. (2017) observed that food resource partitioning between Atlantic salmon Salmo salar L. and Alpine bullhead Cottus poecilopus Heckel was highest at sites with the highest prey diversity and, moreover, that variation in food resource partitioning was best described by a model that included prey diversity as the sole explanatory variable. Similarly, there was a negative influence of prey diversity on trophic niche overlap in this study.

A number of studies have demonstrated that competition can have negative impacts on fish growth, survival or fitness (e.g. Werner \& Gilliam, 1984; Persson, 1983a, 1987; Byström et al., 1998; Britton et al., 2018; Fletcher et al., 2019). In spite of the

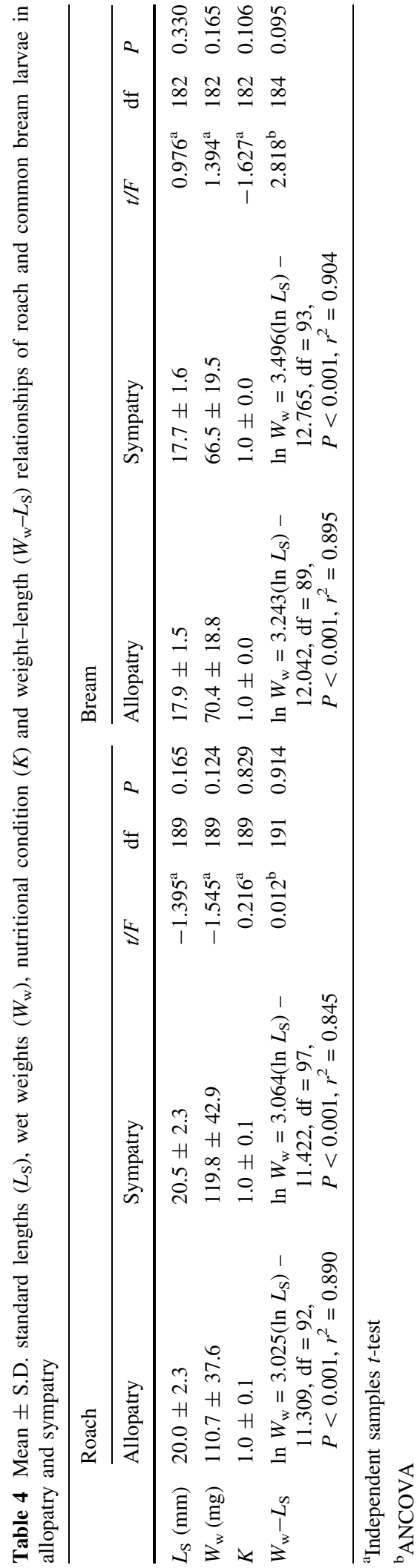


differences in foraging ecology observed in this study, there were no significant differences in the growth or condition of roach or bream larvae in allopatry and sympatry (cf., Britton et al., 2018), suggesting that the strength of competition and/or the duration of the experiment were insufficient to have a measurable effect. It seems unlikely, however, that the duration of the experiment was insufficient as the majority of the larval period, when competition is generally believed to be of greatest significance (Persson \& Greenberg, 1990; Beaugrand et al., 2003), was studied. Other possible explanations include that the fish density was too low, but this also seems unlikely as it was more than an order-of-magnitude higher than in some successful experiments of density-dependent growth (e.g. Byström et al., 1998; Byström \& García-Berthou, 1999; Fletcher et al., 2019). However, although absolute density was constant, and comparable with those observed in the wild (e.g. Nunn et al., 2007a), 'effective density' varied as a result of temporal fluctuations in prey abundance. There could thus have been temporal variations in both the occurrence or strength (a product of predator and prey abundance) and direction (a product of species-specific capacities to forage on particular prey) of competition, the latter of which could potentially mask any effects on growth and condition.

This study demonstrates that interspecific interactions are complex and dynamic, even when most extraneous factors are constant (e.g. competitor abundance) or comparable (e.g. competitor size, prey abundance, water temperature) across treatments, and that traditional indicators, such as growth rates and nutritional condition, are not necessarily capable of detecting short-term or variable incidences of competition. This is important because short-term or variable incidences of competition could have cascading effects on food-web complexity and dynamics, even when no impacts on growth rates or condition are detected, as different prey occupy contrasting positions in the food web (Nakazawa, 2015; SánchezHernández, 2016). This is particularly the case for highly abundant larval and juvenile fishes, which can have a major influence on the abundance and composition of prey assemblages through top-down mechanisms (Mehner \& Thiel, 1999). It is therefore essential that environmental managers ensure that sufficient habitat diversity, and therein diversity, size ranges and abundance of food resources, is available to allow adequate specialisation and segregation of species and life stages, especially as relative competitive abilities can vary between habitats (Diehl, 1988). Similar to the concept of condition-specific competition, when competitive abilities vary along environmental gradients (Taniguchi \& Nakano 2000; Alcaraz et al., 2008), the impacts of interspecific interactions on trophic niches, niche breadths, prey selection, growth and condition are dynamic and likely vary according to temporal fluctuations in prey availability.

Acknowledgments We thank the Environment Agency for allowing us to conduct the experiments at Calverton Fish Farm, and Anita Franco, Dom Henri, Domino Joyce, Will Mayes and Mike Rogerson for constructive criticism of the manuscript. The study was funded by Environment Agency Science Project No. SC060048/SR. The views are those of the authors and not necessarily the Environment Agency.

Open Access This article is licensed under a Creative Commons Attribution 4.0 International License, which permits use, sharing, adaptation, distribution and reproduction in any medium or format, as long as you give appropriate credit to the original author(s) and the source, provide a link to the Creative Commons licence, and indicate if changes were made. The images or other third party material in this article are included in the article's Creative Commons licence, unless indicated otherwise in a credit line to the material. If material is not included in the article's Creative Commons licence and your intended use is not permitted by statutory regulation or exceeds the permitted use, you will need to obtain permission directly from the copyright holder. To view a copy of this licence, visit http://creativecommons.org/licenses/by/4.0/.

Authors' contributions AN, IC, GP, SA and AH conceived the study and designed the methodology, LV, AN and JB collected the data, AN and KM analysed the data, and AN led the writing of the manuscript. All authors contributed critically to the drafts and gave final approval for publication.

\section{References}

Alcaraz, C., A. Bisazza \& E. García-Berthou, 2008. Salinity mediates the competitive interactions between invasive mosquitofish and an endangered fish. Oecologia 155: 205-213.

Anderson, M. J., 2001. Permutation tests for univariate or multivariate analysis of variance and regression. Canadian Journal of Fisheries and Aquatic Sciences 58: 626-639.

Anderson, M. J., R. N. Gorley \& K. R. Clarke, 2008. PERMANOVA+ for PRIMER: Guide to Software and Statistical Methods. PRIMER-E, Plymouth.

Aschehoug, E. T., R. Brooker, D. Z. Atwater, J. L. Maron \& R. M. Callaway, 2016. The mechanisms and consequences of 
interspecific competition among plants. Annual Review of Ecology, Evolution, and Systematics 47: 263-281.

Bagenal, T. B. \& F. W. Tesch, 1978. Age and growth. In Bagenal, T. B. (ed.), Methods for the Assessment of Fish Production in Fresh Waters. Blackwell Scientific Publications, Oxford: 101-136.

Beaugrand, G., K. M. Brander, J. A. Lindley, S. Souissi \& P. C. Reid, 2003. Plankton effect on cod recruitment in the North Sea. Nature 426: 661-664.

Begon, M., C. R. Townsend \& J. L. Harper, 2006. Ecology: From Individuals to Ecosystems. Blackwell Publishing, Oxford.

Bolnick, D. I., T. Ingram, W. E. Stutz, L. K. Snowberg, O. L. Lau \& J. S. Paull, 2010. Ecological release from interspecific competition leads to decoupled changes in population and individual niche width. Proceedings of the Royal Society B 277: 1789-1797.

Bray, J. R. \& J. T. Curtis, 1957. An ordination of the upland forest communities of Southern Wisconsin. Ecological Monographs 27: 325-349.

Britton, J. R., A. Ruiz-Navarro, H. Verreycken \& F. AmatTrigo, 2018. Trophic consequences of introduced species: comparative impacts of increased interspecific versus intraspecific competitive interactions. Functional Ecology 32: 486-495.

Buoro, M., J. D. Olden \& J. Cucherousset, 2016. Global Salmonidae introductions reveal stronger ecological effects of changing intraspecific compared to interspecific diversity. Ecology Letters 19: 1363-1371.

Byström, P. \& E. García-Berthou, 1999. Density dependent growth and size specific competitive interactions in young fish. Oikos 86: 217-232.

Byström, P., L. Persson \& E. Wahlström, 1998. Competing predators and prey: juvenile bottlenecks in whole-lake experiments. Ecology 79: 2153-2167.

Cano-Rocabayera, O., S. Vargas-Amengual, C. Aranda, A. de Sostoa \& A. Maceda-Veiga, 2020. Mosquito larvae consumption in turbid waters: the role of the type of turbidity and the larval stage in native and invasive fish. Hydrobiologia 847: 1371-1381.

Clarke, K. R. \& R. M. Warwick, 2001. Change in Marine Communities: an Approach to Statistical Analysis and Interpretation. PRIMER-E, Plymouth.

Cucherousset, J., J. C. Aymes, F. Santoul \& R. Céréghino, 2007. Stable isotope evidence of trophic interactions between introduced brook trout Salvelinus fontinalis and native brown trout Salmo trutta in a mountain stream of southwest France. Journal of Fish Biology 71(Supplement D): 210-223.

Diehl, S., 1988. Foraging efficiency of three freshwater fishes: effects of structural complexity and light. Oikos 53: 207-214.

Fletcher, C. M., S. F. Collins, M. A. Nannini \& D. H. Wahl, 2019. Competition during early ontogeny: effects of native and invasive planktivores on the growth, survival, and habitat use of bluegill. Freshwater Biology 64: 697-707.

Garner, P., 1996. Microhabitat use and diet of 0+ cyprinid fishes in a lentic, regulated reach of the River Great Ouse, England. Journal of Fish Biology 48: 367-382.

Gilby, B. L., I. R. Tibbetts, J. Van Bourg, L. Delisle \& D. D. Burfeind, 2017. Predator presence alters prey diet composition but not quantity in tide pool fish interactions. Hydrobiologia 795: 257-265.

Hardin, G., 1960. The competitive exclusion principle. Science 131: 1292-1297.

Hayden, B., D. Pulcini, M. Kelly-Quinn, M. O’Grady, J. Caffrey, A. McGrath \& S. Mariani, 2010. Hybridization between two cyprinid fishes in a novel habitat: genetics, morphology and life-history traits. BMC Evolutionary Biology 10: 169.

Hillebrand, H. \& B. Matthiessen, 2009. Biodiversity in a complex world: consolidation and progress in functional biodiversity research. Ecology Letters 12: 1405-1419.

Jackson, M. C., R. Allen, J. Pegg \& J. R. Britton, 2013. Do trophic subsidies affect the outcome of introductions of a non-native freshwater fish? Freshwater Biology 58: 2144-2153.

Jarolím, O., J. Kubečka, M. Čech, M. Vašek, J. Peterka \& J. Matĕna, 2010. Sinusoidal swimming in fishes: the role of season, density of large zooplankton, fish length, time of the day, weather condition and solar radiation. Hydrobiologia 654: 253-265.

Kottelat, M. \& J. Freyhof, 2007. Handbook of European Freshwater Fishes. Publications Kottelat, Cornol.

Krabbenhoft, C. A., A. S. Burdett \& T. F. Turner, 2017. Direct and indirect effects of predatory young-of-year fishes in a dryland river food web. Freshwater Biology 62: 1410-1421.

Mehner, T. \& R. Thiel, 1999. A review of predation impact by $0+$ fish on zooplankton in fresh and brackish waters of the temperate northern hemisphere. Environmental Biology of Fishes 56: 169-181.

Miller, T. E. X. \& V. H. W. Rudolph, 2011. Thinking inside the box: community-level consequences of stage structured populations. Trends in Ecology and Evolution 26: 457-466.

Nakazawa, T., 2015. Ontogenetic niche shifts matter in community ecology: a review and future perspectives. Population Ecology 57: 347-354.

Nunn, A. D., J. P. Harvey \& I. G. Cowx, 2007a. Benefits to $0+$ fishes of connecting man-made waterbodies to the lower River Trent, England. River Research and Applications 23: 361-376.

Nunn, A. D., J. P. Harvey \& I. G. Cowx, 2007b. The food and feeding relationships of larval and $0+$ year juvenile fishes in lowland rivers and connected waterbodies. I. Ontogenetic shifts and interspecific diet similarity. Journal of Fish Biology 70: 726-742.

Nunn, A. D., J. P. Harvey \& I. G. Cowx, 2007c. The food and feeding relationships of larval and $0+$ year juvenile fishes in lowland rivers and connected waterbodies. II. Prey selection and the influence of gape. Journal of Fish Biology 70: 743-757.

Nunn, A. D., L. H. Tewson \& I. G. Cowx, 2012. The foraging ecology of larval and juvenile fishes. Reviews in Fish Biology and Fisheries 22: 377-408.

Persson, A. \& C. Brönmark, 2002. Foraging capacities and effects of competitive release on ontogenetic diet shift in bream, Abramis brama. Oikos 97: 271-281.

Persson, L., 1983a. Effects of intra- and interspecific competition on dynamics and size structure of a perch Perca 
fluviatilis and a roach Rutilus rutilus population. Oikos 41: 126-132.

Persson, L., 1983b. Food consumption and the significance of detritus and algae to intraspecific competition in roach Rutilus rutilus in a shallow eutrophic lake. Oikos 41: 118-125.

Persson, L., 1987. The effects of habitat and season on competitive interactions between roach (Rutilus rutilus) and perch (Perca fluviatilis). Oecologia 73: 170-177.

Persson, L. \& L. A. Greenberg, 1990. Juvenile competitive bottlenecks: the perch (Perca fluviatilis)-roach (Rutilus rutilus) interaction. Ecology 71: 44-56.

Rodríguez-Lozano, P., I. Verkaik, A. Maceda-Veiga, M. Monroy, A. de Sostoa, M. Rieradevall \& N. Prat, 2016. A traitbased approach reveals the feeding selectivity of a small endangered Mediterranean fish. Ecology and Evolution 6: 3299-3310.

Sánchez-Hernández, J., 2016. Do age-related changes in feeding habits of brown trout alter structural properties of food webs? Aquatic Ecology 50: 685-695.

Sánchez-Hernández, J., H.-M. Gabler \& P.-A. Amundsen, 2017. Prey diversity as a driver of resource partitioning between river-dwelling fish species. Ecology and Evolution 7: 2058-2068.

Sánchez-Hernández, J., A. D. Nunn, C. E. Adams \& P.-A. Amundsen, 2019. Causes and consequences of ontogenetic dietary shifts: a global synthesis using fish models. Biological Reviews 94: 539-554.

Schellekens, T., A. M. De Roos \& L. Persson, 2010. Ontogenetic diet shifts result in niche partitioning between two consumer species irrespective of competitive abilities. American Naturalist 176: 625-637.

Schoener, T. W., 1974. Resource partitioning in ecological communities. Science 185: 27-39.

Taniguchi, Y. \& S. Nakano, 2000. Condition-specific competition: implications for the altitudinal distribution of stream fishes. Ecology 81: 2027-2039.

Tewson, L. H., I. G. Cowx \& A. D. Nunn, 2016. Diel variations in the assemblage structure and foraging ecology of larval and $0+$ year juvenile fishes in a man-made floodplain waterbody. Journal of Fish Biology 88: 1486-1500.

Townsend, C. R., I. J. Winfield, G. Peirson \& M. Cryer, 1986. The response of young roach Rutilus rutilus to seasonal changes in abundance of microcrustacean prey: a field demonstration of switching. Oikos 46: 372-378.

Tran, T. N. Q., M. C. Jackson, D. Sheath, H. Verreycken \& J. R. Britton, 2015. Patterns of trophic niche divergence between invasive and native fishes in wild communities are predictable from mesocosm studies. Journal of Animal Ecology 84: 1071-1080.

Vanderploeg, H. A. \& D. Scavia, 1979. Calculation and use of selectivity coefficients of feeding: zooplankton grazing. Ecological Modelling 7: 135-149.

Washington, H. G., 1984. Diversity, biotic and similarity indices: a review with special relevance to aquatic ecosystems. Water Research 18: 653-694.

Werner, E. E. \& J. F. Gilliam, 1984. The ontogenetic niche and species interactions in size-structured populations. Annual Review of Ecology and Systematics 15: 393-425.

Werner, E. E. \& D. J. Hall, 1974. Optimal foraging and the size selection of prey by bluegill sunfish (Lepomis macrochirus). Ecology 55: 1042-1052.

Werner, E. E. \& D. J. Hall, 1976. Niche shifts in sunfishes: experimental evidence and significance. Science 191: 404-406.

Wiens, J. A., 1993. Fat times, lean times and competition among predators. Trends in Ecology and Evolution 8: 348-349.

Winfield, I. J. \& C. R. Townsend, 1988. Factors affecting prey selection by young bream Abramis brama and roach $R u$ tilus rutilus: insights provided by parallel studies in laboratory and field. Environmental Biology of Fishes 21: 279-292.

Winfield, I. J., G. Peirson, M. Cryer \& C. R. Townsend, 1983. The behavioural basis of prey selection by underyearling bream (Abramis brama (L.)) and roach (Rutilus rutilus (L.)). Freshwater Biology 13: 139-149.

Young, K. A., 2004. Asymmetric competition, habitat selection, and niche overlap in juvenile salmonids. Ecology 85: 134-149.

Publisher's Note Springer Nature remains neutral with regard to jurisdictional claims in published maps and institutional affiliations. 